\title{
ALGUNS DADOS RELATIVOS AO PROJETO DE PESQUISA "ARQUEOLOGIA DE UM SANTUÁRIO: O HERAION DE DELOS, GRÉCIA"
}

\section{Introdução e resumo \\ do projeto de pesquisa}

Em 1990, o ex-Diretor da École Française d'Athènes, Prof. Dr. Olivier Picard, encarregou-me de retomar o conjunto do dossiê do Heraion de Delos com vistas a uma nova publicação: escavado em 1911 por Pierre Roussel, o monumento e as oferendas votivas foram publicadas sucessivamente por Charles Dugas, André Plassart e Alfred Laumonier de 1928 a 1956. Foram realizadas sondagens em 1953 e 1958 por Paul Bernard e, em 1964, por Jean Ducat.

$O$ reexame deste material arqueológico levou-me a questionar a classificação das inúmeras categorias cerâmicas, das terracotas, dos fragmentos arquitetônicos e, do mesmo modo, a cronologia dos objetos e do monumento: dois templos, um mais antigo que o outro, um altar, um muro de períbolo, um muro de sustentação do terraço.

As três campanhas de estudo realizadas em 1990, 1996 e 1999 revelaram, sobretudo a partir do exame do material das sondagens de Paul Bernard e de Jean Ducat, a presença de fragmentos cerâmicos do Geométrico Recente (750-700 a.C.) o que reforçou desta maneira uma data mais antiga para o início do culto de Hera neste santuário; e também do material cerâmico ático com figuras vermelhas, mais recentes do que se acreditava até então, isto é, datado de após 480 a.C. Isto coloca o problema do início do santuário e da cronologia do templo mais antigo, o Heraion I, e da data do templo mais recente, o Heraion II. A análise dos artefatos, todos objetos votivos consagrados à deusa Hera, orienta também para o conhecimento da história do culto praticado em honra a esta deusa e apóia uma melhor datação das outras estruturas arquitetônicas subsistentes no santuário, a saber, o altar, o muro de períbolo e o muro de sustentação do terraço dos templos.

Com base nestes dados, tenho aprofundado as seguintes questões em várias etapas de pesquisas:

1. O santuário de Hera (Heraion), suas estruturas arquitetônicas, seu significado, sua caracterização técnica, bem como sua cronologia exata.

2. As oferendas votivas: vasos e terracotas, com análises detalhadas, classificação, iconografia e cronologia.

3. O Heraion e as questões históricas: pela freqüentação do santuário, cuja origem será conhecida pela determinação dos centros de produção das oferendas, estudo e tipologia das relações entre as cidades gregas das Cíclades, da Grécia continental e da Jônia e o santuário de Hera em Delos.

4. O Heraion e as questões antropológicas: análise dos objetos como oferendas votivas, a noção de dom a uma divindade; definição de conceitos como tradição, inovação, assimilação e aculturação de formas e decoração dos exvotos.

\section{O Heraion de Delos: pesquisas da campanha de $\mathbf{2 0 0 0}$}

Durante o período de 75 dias na Grécia, incluindo 30 dias em Delos e 45 dias em Atenas, realizou-se um programa incluindo pesquisas de campo em Delos (estudo das estruturas arquitetônicas no sítio arqueológico e da cerâmica na Reserva Técnica do Museu local), em Míconos, no Museu Ar-

(1) Com Bolsa de Pesquisa no Exterior, FAPESP. 
queológico, e, em Atenas, nos locais da Escola Francesa de Arqueologia, pesquisas documentais na Biblioteca, Fototeca, Planoteca e Arquivo, bem como estudos comparativos com material cerâmico conservado nos museus Benaki, Cicládico e Cerâmico.

\section{As estruturas arquitetônicas no sítio arqueológico (Fig. 1)}

\subsection{O Heraion I (Fig. 2)}

O Heraion I, templo de Hera mais antigo, foi descoberto no interior da cella do Heraion II, templo de Hera mais recente. Para uma melhor análise das estruturas, procedeu-se em primeiro lugar a uma limpeza geral, que possibilitou uma compreensão mais nítida das construções. Este primeiro templo foi edificado com placas de gneis dispostas com uma certa regularidade. De forma trapezoidal, tem as seguintes dimensões externas: muro $\mathrm{N}=$ $3,40 \mathrm{~m}$; muro $\mathrm{S}=2,85 \mathrm{~m}$; muro $\mathrm{O}=2,77 \mathrm{~m}$; muro $\mathrm{E}$ $=2,87 \mathrm{~m}$. A abertura da porta, orientada ao $\mathrm{S}$, tem $0,98 \mathrm{~m}$ de largura.

Em sua parte posterior, existe uma banqueta cultual, com $0,48 \mathrm{~m}$ de altura acima do rochedo e com $0,20 \mathrm{~m}$ aproximadamente acima do nível antigo. Ela ocupa quase a metade deste pequeno naos e é constituída por um recheio de terra e de pedras que limitam os murinhos em placas finas de gneis e que recobrem as lajes de gneis com dimensões variáveis.

Há vestígios do teto, pois alguns restos de cobertura foram recolhidos nas escavações de 1911: encontram-se na Reserva Técnica, ainda para serem analisados detidamente, inúmeros fragmentos de telhas planas e alguns fragmentos de simae, de terracota: a decoração da sima consta de palmetas e de flor de lótus pintadas em vermelho púrpura (Fig. 3).

É provável que o Heraion I possuísse à sua volta uma colunata de madeira, uma vez que foram encontradas pequenas bases troncocônicas de mármore que são, na verdade, suportes de colunas. $\mathrm{O}$ número dos fragmentos destas bases conservadas indicaria uma disposição períptera e colunas bem próximas, talvez quatro para cada face do templo.

\subsection{O Heraion II (Fig. 4)}

Este segundo templo de Hera forma um retângulo de $13,05 \mathrm{~m}, 13,8 \mathrm{~m} \mathrm{~N}-\mathrm{S}$ por $6,95 \mathrm{~m}$, 6,97m O-E, com fachada ao sul constituída de duas colunas in antis. Trata-se de um templo de ordem dórica, composta de um pronaos e de uma cella. $\mathrm{O}$ alicerce é feito de gneis e de granito; na parte oeste, dois tambores de mármore branco aí estão excepcionalmente dispostos. O aparelhamento externo da elevação bem como o pronaos são constituídos de blocos retangulares de mármore branco, o piso da cella era feito de pequenos seixos também brancos justapostos em uma camada de cimento pouco espessa estabelecida sobre um leito de pedrinhas.

Durante a escavação de 1911, antes da escavação do templo antigo (Heraion I), descobriram-se na cella os alicerces de uma grande base retangular disposta um pouco obliquamente, cerca de $2,75 \mathrm{~m}$ ao $\mathrm{N}$ da soleira. Estas fundações foram retiradas e recompostas sobre uma pequena esplanada ao $\mathrm{N}$ do edifício; feitas de lajes de gneis ou de mármore, medem $3,70 \mathrm{~m}$ de largura e $2,70 \mathrm{~m}$ de profundidade, conservam ainda na parte superior quatro blocos de mármore branco. Certamente esta fundação no interior do novo templo devia suportar a estátua de culto.

No pronaos, duas banquetas laterais, a leste e oeste, deviam servir como assento para os fiéis que vinham prestar seu culto à deusa.

O monumento comportando os dois templos (Heraion I e II), o mais antigo embutido no mais recente, está cercado por um recinto retangular, os muros de períbolo, que parece ser paralelo ao templo I, apesar de as interpretações feitas até o momento verem-no como paralelo ao templo II. Este períbolo constitui-se de blocos de granito e de gneis e está mais bem conservado no lado sul.

Diante do Heraion, fora do períbolo, encontra-se o altar: sobre os alicerces de lajes de gneis e blocos de granito repousa uma enthynteria de mármore branco e placas de gneis com contornos irregulares completam esta base no interior. A situação deste altar fora do muro de períbolo é bastante problemática se nós entendermos o muro de períbolo como recinto do Heraion II. Ora, parece 
Notas - Revista do Museu de Arqueologia e Etnologia, Sāo Paulo, 10: 329-336, 2000

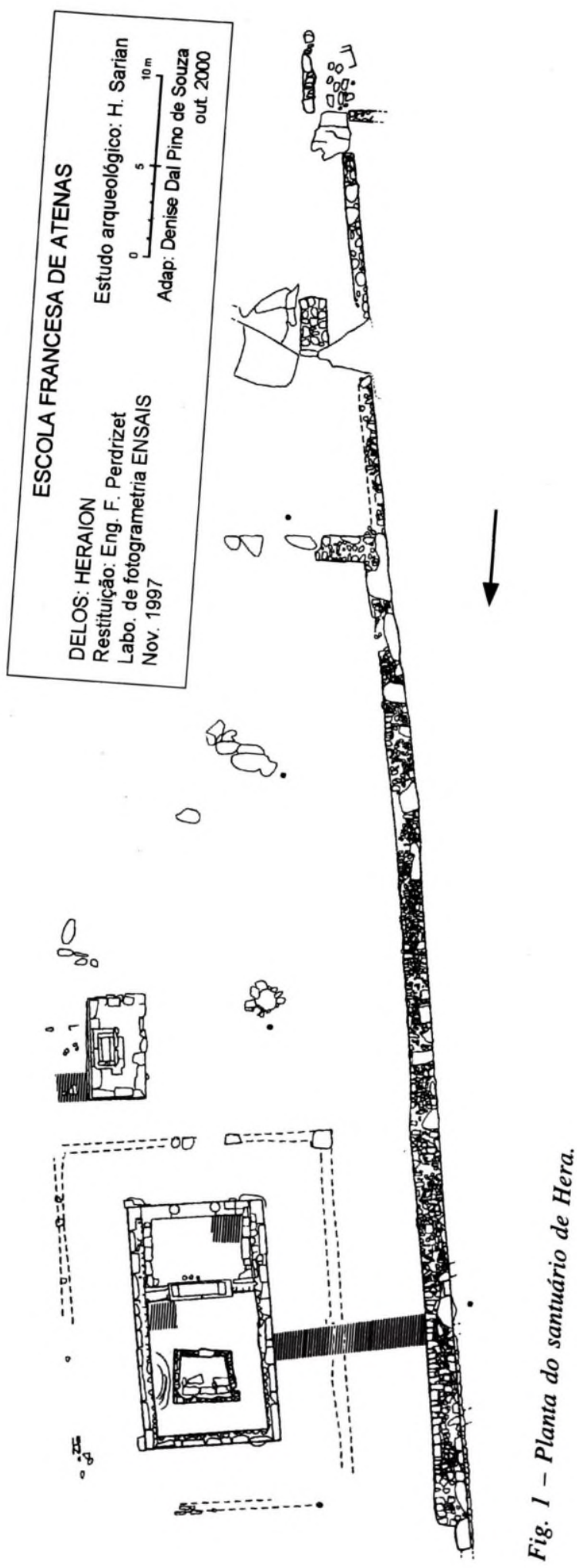


Notas - Revista do Museu de Arqueologia e Etnologia, São Paulo, 10: 329-336, 2000.

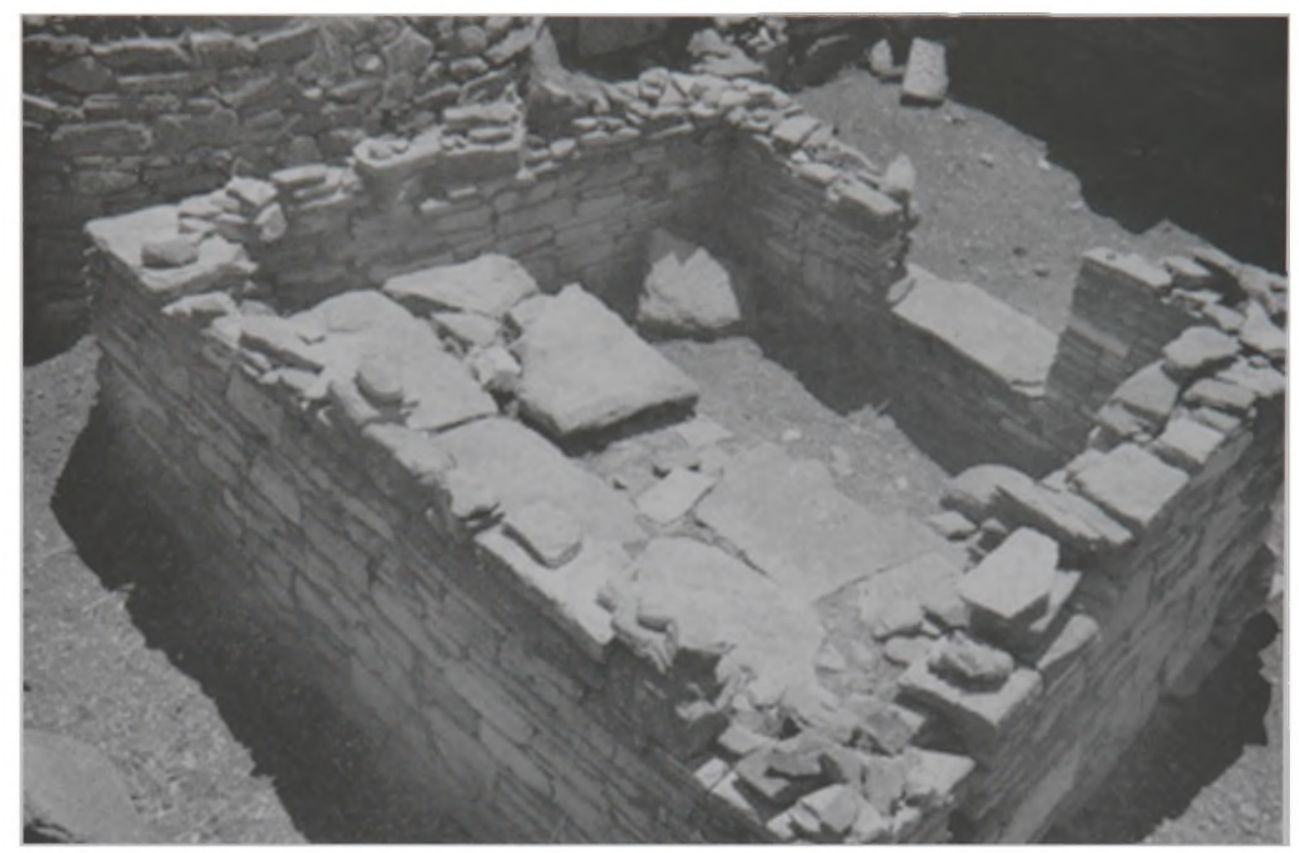

Fig. 2 - Heraion I. Foto EFA, Philippe Collet.

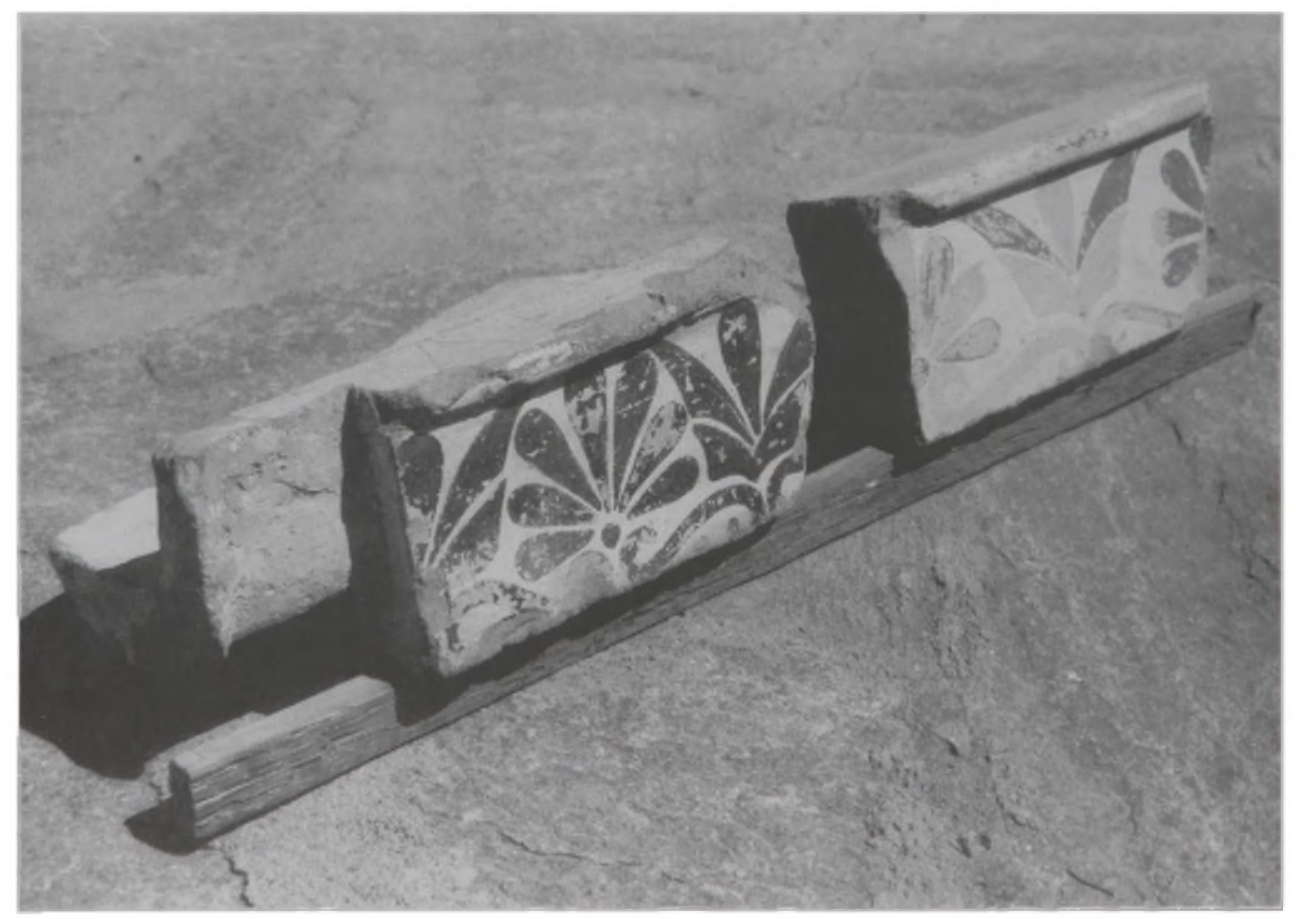

Fig. 3 - Fragmentos arquitetônicos. Foto EFA. 


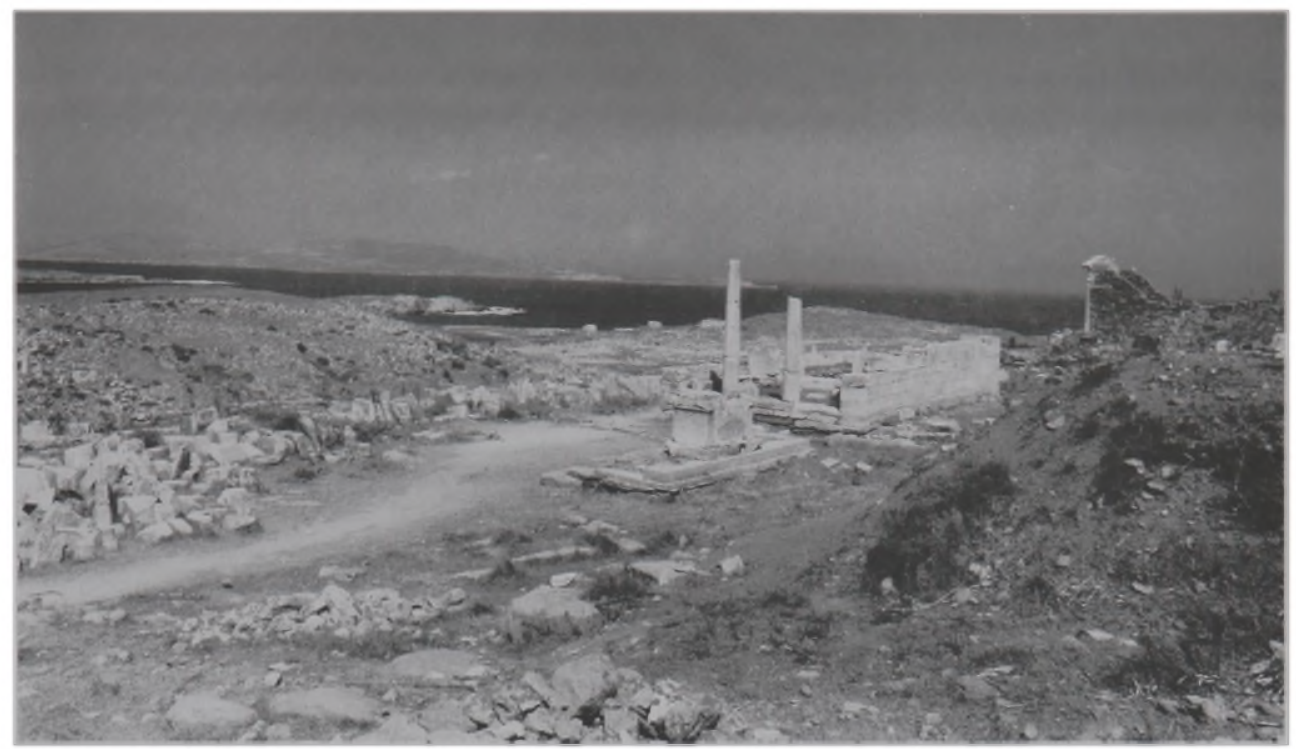

Fig. 4 - O Heraion II. Foto EFA, Phillipe Collet.

estranho que tanto o altar quanto boa parte do terraço do templo ficassem fora do recinto sagrado. Daí, a interpretação acima, de que o períbolo depende mais do Heraion I do que do Heraion II, poderá esclarecer esta questão.

$\mathrm{Tal}$ altar, pelo tipo de grampo em duplo $\mathrm{T}$ entre as lajes de mármore, por tratar-se de um altar dotado de frontões e pelo emprego de lajes de gneis no alicerce, parece datar do séc. IV a.C.

$\mathrm{O}$ conjunto de estruturas arquitetônicas é enquadrado por um muro de sustentação do terraço, cujo aparelhamento oeste é visível e caracterizado por enormes blocos de granito com apenas a face externa sumariamente aplainada. A técnica deste muro de terraço parece indicar uma data no período arcaico, porém a cronologia mais específica e melhor determinada exigirá um estudo mais aprofundado.

Algumas questões cronológicas se apresentam: em primeiro lugar, deve-se salientar que o Heraion, com todas as suas construções, tem uma cronologia um tanto quanto incerta: o Heraion I, como bem mencionamos acima, tem sido datado do séc. VII a.C., com base no depósito votivo que se compõe de inúmeros vasos cicládicos, protocoríntios e da Grécia de Leste desse período. Ora, não só encontramos vasos geométricos, neste depósito votivo, quanto observamos fragmentos do período geométrico recente no material proveniente sobretudo das sondagens de 1964 realizadas por Jean Ducat. Seria preciso considerar melhor estes achados e levá-los em conta não só no que respeita ao início da prática cultual mas também no que se refere às estruturas do Heraion I.

A cronologia do templo mais recente, o Heraion II, tem sido fixada entre o final do século VI a.C. e os primeiros anos do século V. Mais uma vez, um reexame dos vasos e fragmentos cerâmicos, desta vez áticos de figuras negras e de figuras vermelhas, aponta para o final do primeiro quartel do século $\mathrm{V}$ a.C. (ou mesmo meados do séc. V a.C.) vale dizer, entre os anos 475 e 450 a.C.

Os muros de períbolo e de sustentação têm uma cronologia insegura e devem ser estudados quanto à técnica de construção e quanto ao relacionamento com os templos de Hera.

\section{A coleção cerâmica conservada no Museu local}

As categorias cerâmicas identificadas por Charles Dugas em 1928 incluem, em um total de um milhar de exemplares (sem contar os fragmentos), vasos cicládicos orientalizantes 
(alguns do final do geométrico); vasos orientalizantes da Grécia de Leste; vasos protocoríntios e coríntios; vasos áticos. Poucos são os exemplares de Creta, Chipre e outras raras localidades ainda a serem determinadas. Nas etapas de estudo de 1990, 1996 e 1999, foi possível reexaminar estes vasos. $\mathrm{Na}$ etapa deste ano, dediquei-me exclusivamente ao estudo dos fragmentos e de alguns pequenos vasos conservados na Reserva Técnica do Museu de Delos. Esta pesquisa foi desenvolvida com a colaboração de dois dos meus orientandos, Fábio Vergara Cerqueira e André Leonardo Chevitarese, os quais usufruíram de uma bolsa de estudos da Escola Francesa de Atenas, precisamente para esta finalidade.

Assim sendo, fizemos a análise de material cerâmico contido em 18 gavetas, num total de aproximadamente 550 exemplares entre pequenos vasos e fragmentos, dentre os quais $50 \%$ foram também fotografados.

As categorias cerâmicas registradas são:

1. Cerâmica cicládica: geométrico, orientalizante (Fig. 5) incluindo os importantes exemplares de pratos provavelmente de Paros, vasos de Naxos, pínakes policromados, e vasos de estilo "meliano".

2. Cerâmica da Grécia de Leste: orientalizante ródio, askoi de Rodes, taças jônicas, aríbalos e enócoas rodo-jônicos; bucchero jônico (Fig. 6).

3. Cerâmica de Corinto incluindo os proto-coríntios e os coríntios propriamente ditos (Fig. 7).

4. Cerâmica ática, incluindo as técnicas de figuras negras e de figuras vermelhas (Figs. 8, 9, 10).

$\mathrm{Na}$ análise destes artefatos, levamos em conta a caracterização e a coloração da argila e do verniz, esta última baseada com rigor na Notice sur le Code de Couleurs des Sols de A. Cailleux (Boubée, Rondel Imp., s/l, s/d).

Por outro lado, muitas comparações foram feitas com os vasos expostos nas vitrinas do Museu, a maioria deles provenientes do Heraion e pertencentes às mesmas categorias cerâmicas.

Vale ressaltar, finalmente, que as datas do material analisado referem-se à $2^{\mathrm{a}}$ metade do séc. VIII a.C. (cerâmica geométrica das Cíclades) até meados do século $\mathrm{V}$ (cerâmica ática de figuras vermelhas), logo, um quadro cronológico de mais de dois séculos e meio.

\section{Perspectivas}

As pesquisas continuarão por ainda alguns anos. Inseridas no Plano Diretor quadrienal da École Française d'Athènes, são parte substancial de um programa prioritário mais amplo incluindo o estudo dos santuários de Delos: uma síntese sobre o santuário de Apolo em preparação sob a responsabilidade de Roland Etienne, Diretor da École Française d'Athènes; as publicações do santuário de Anios por Francis Prost, ex-membro da EFA e professor na Universidade de Rennes, e do santuário de Serapis por Hélène Siard, também ex-membro da EFA e professora da Universidade de Limoges.

No tocante ao Santuário de Hera, pretende-se proceder a uma série de escavações (ver Fig. 1, indicações com hachuras) com o

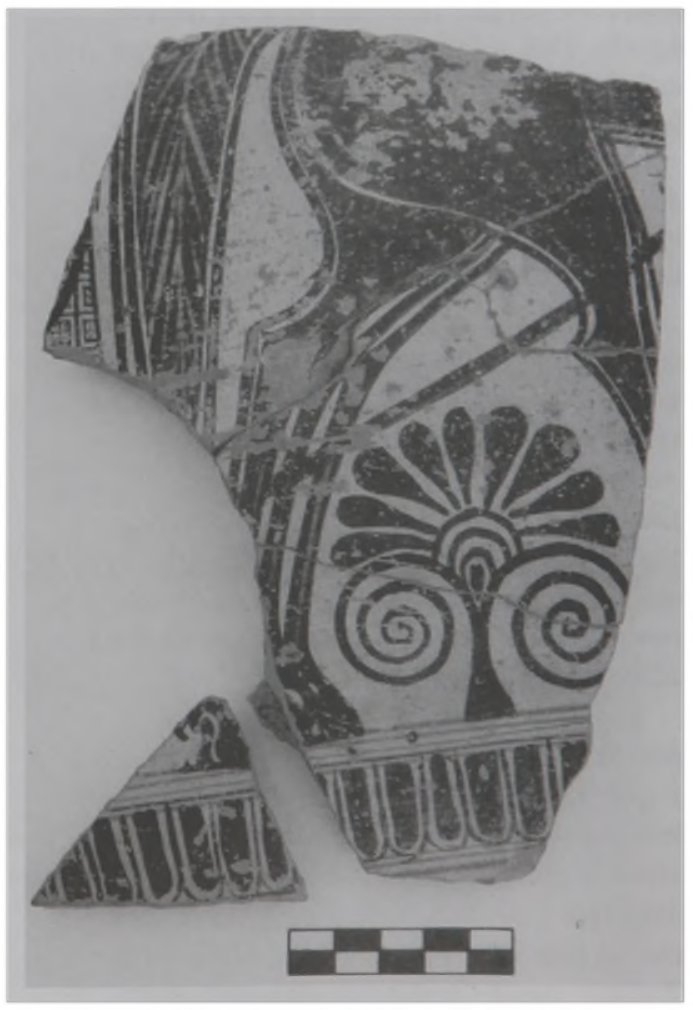

Fig. 5 - Fragmento de ânfora cicládica orientalizante. Foto H. Sarian. 
objetivo principal de situar melhor a cronologia das estruturas. Estas escavações, previstas para 2002, orientarão as possibilidades de outras pesquisas de campo para o futuro. Por

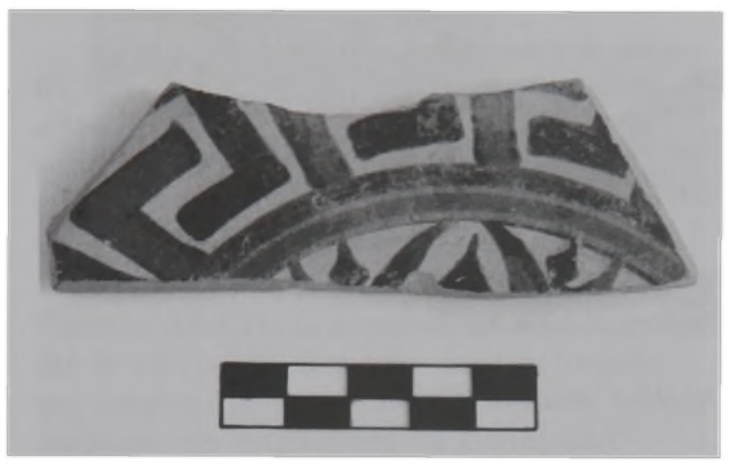

Fig. 6 - Fragmento de prato da Grécia de Leste, Rodes. Foto H. Sarian.

outro lado, prosseguir-se-ão os estudos do material votivo conservado no Museu local procedente das escavações de 1911 e, logicamente, do material que por ventura for descoberto nas escavações a serem realizadas a partir de 2002.

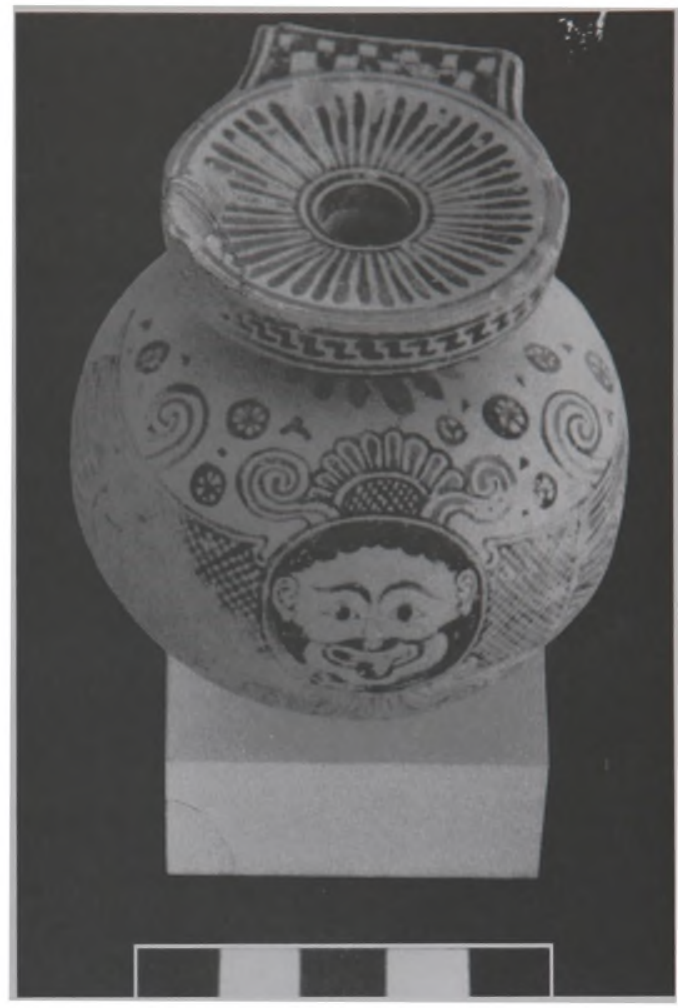

Fig. 7 - Aribalo proto-coríntio. Foto H. Sarian.

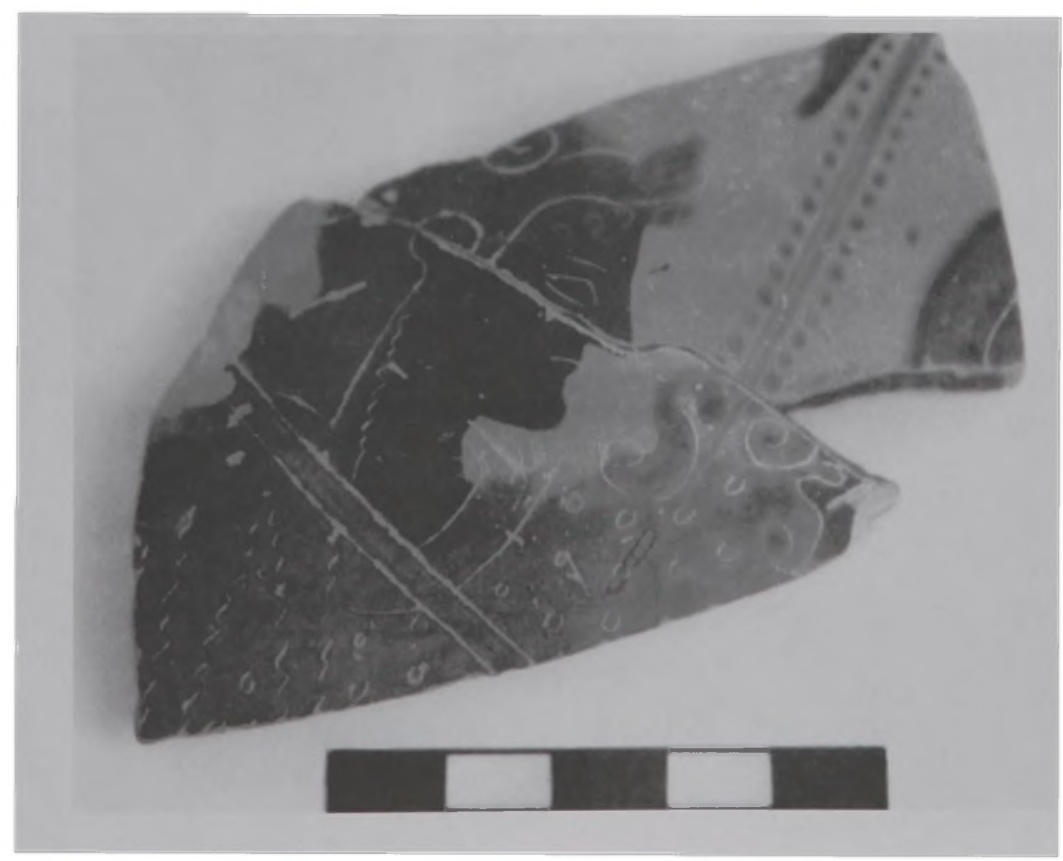

Fig. 8 - Fragmento de vaso ático de figuras negras. Foto H. Sarian. 


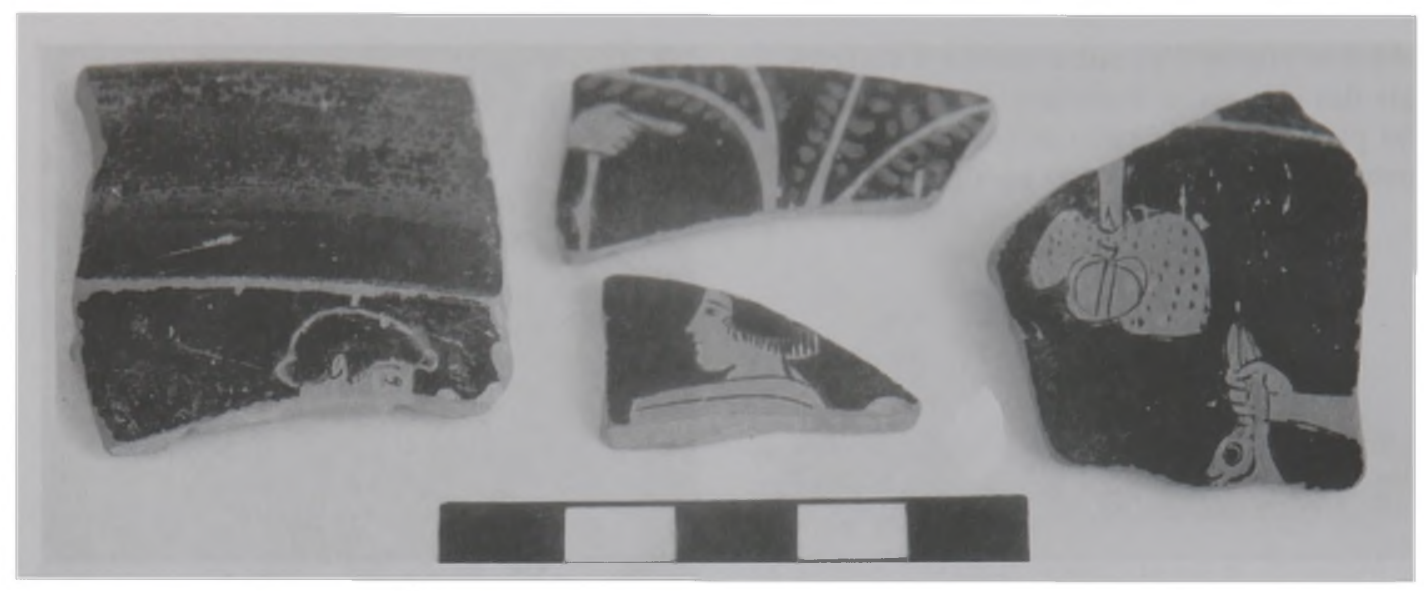

Fig. 9 - Fragmentos de vasos áticos de figuras vermelhas. Foto H. Sarian.

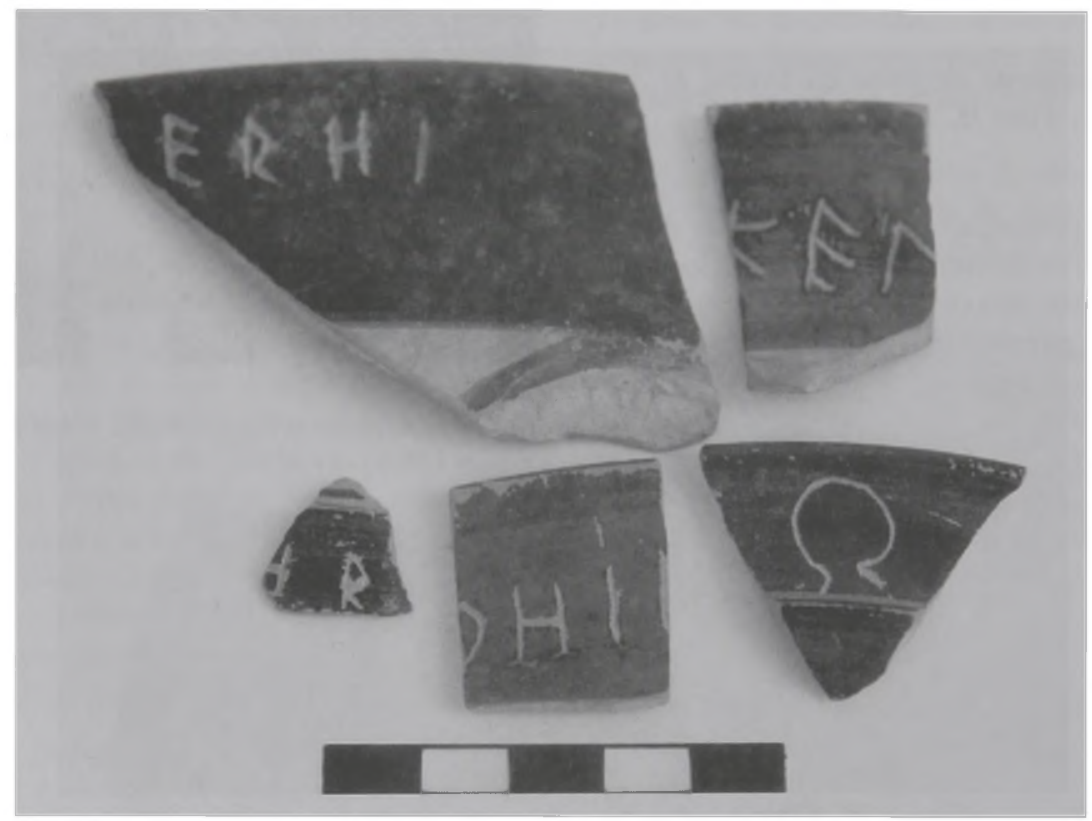

Fig. 10 - Fragmentos de vasos áticos com inscrições dedicatórias à deusa Hera. Foto H. Sarian.

\section{Bibliografia básica}

DUGAS, C.

1928 Les vases de l'Héraion. Paris: De Boccard. (EAD, X).

LAUMONIER, A.

1956 Les figurines de terre cuite. Paris: De Boccard. (EAD, XXIII).

Recebido para publicação em 6 de dezembro de 2000.

\section{PLASSART, A.}

1928 Les sanctuaires et les cultes du Mont Cynthe. Paris: De Boccard. (EAD, XI).

\section{Haiganuch Sarian*}

(*) Museu de Arqueologia e Etnologia da Universidade de São Paulo. 